\title{
In Vitro Study of the Enzymatic and Nonenzymatic Conjugation of Treosulfan with Glutathione
}

\author{
Michał Romański ${ }^{1}\left[\right.$ · Franciszek K. Główka ${ }^{1}$
}

Published online: 16 April 2019

(c) The Author(s) 2019

\begin{abstract}
Background and Objectives Treosulfan (dihydroxybusulfan), licensed for the treatment of ovarian carcinoma, is investigated in clinical trials as a myeloablative agent for conditioning prior to hematopoietic stem cell transplantation. Clinical experience shows that treosulfan exhibits lower organ toxicity than busulfan, including hepatotoxicity. Elimination of busulfan primarily via enzymatic conjugation with glutathione (GSH) in the liver is considered to be the main cause of the drug's hepatotoxicity and interpatient clearance variability. It is believed that treosulfan undergoes no hepatic metabolism but empirical evidence is lacking. The aim of this kinetic study was to verify if treosulfan is capable of conjugating with GSH.

Methods Treosulfan $(200 \mu \mathrm{M})$ was incubated at $\mathrm{pH} 7.2$ and $37^{\circ} \mathrm{C}$ with $5 \mathrm{mM} \mathrm{GSH}$ in the presence or absence of human liver cytosol, the main store of glutathione $S$-transferase in the body. Concentrations of treosulfan were determined using liquid chromatography-tandem mass spectrometry and then subjected to kinetic analysis.

Results The decay of treosulfan in the solution followed a one-exponential model in the presence of either GSH or liver cytosol and GSH. The first-order reaction rate constants $\left(0.25 \mathrm{~h}^{-1}\right)$ did not differ statistically from those found for treosulfan conversion in $\mathrm{pH} 7.2$ buffer only.

Conclusion Treosulfan does not undergo either spontaneous or enzymatic conjugation with GSH at a noticeable rate. The result indicates that the clearance of treosulfan is independent of glutathione $S$-transferase activity, GSH stores, and coadministration of drugs utilizing the GSH metabolic pathway.
\end{abstract}

\section{Key Points}

Treosulfan does not undergo either nonenzymatic or human liver cytosol glutathione $S$-transferase-mediated conjugation with glutathione.

Glutathione $S$-transferase activity and GSH stores should not influence the clearance of treosulfan.

Michał Romański

michalroman@ump.edu.pl

1 Department of Physical Pharmacy and Pharmacokinetics, Poznan University of Medical Sciences, 6 Święcickiego Street, 60-781 Poznań, Poland

\section{Introduction}

Treosulfan (dihydroxybusulfan, Fig. 1) is licensed in several European countries for the treatment of advanced ovarian carcinoma [1]. Unlike busulfan, treosulfan is a prodrug in which biological activity relies upon a nonenzymatic $\mathrm{pH}$ dependent conversion to DNA alkylating epoxides- $(2 S, 3 S)$ 1,2-epoxybutane-3,4-diol 4-methanesulfonate (EBDM) and $(2 S, 3 S)$-1,2:3,4-diepoxybutane (DEB) [2-4]. For the past two decades, treosulfan has been increasingly used worldwide in a clinical trial setting in conditioning prior to hematopoietic stem cell transplantation (HSCT) as an alternative to busulfan, especially in children and high-risk patients [5-7]. The key rationale for this application is low organ toxicity, including hepatotoxicity, of the myeloablative doses of treosulfan compared with busulfan [5-9].

It is well known that busulfan undergoes elimination from the body primarily via enzymatic conjugation with glutathione (GSH) [10]. The polymorphism of glutathione $S$-transferase (GST), changes in enzyme activity with age, and the co-administration of drugs being substrates, inducers 
Fig. 1 Activation pathway of the prodrug treosulfan and the structure of busulfan

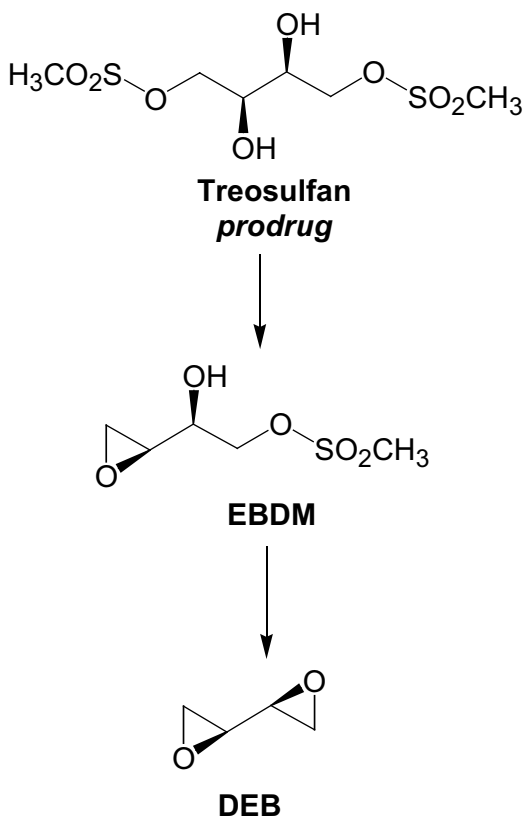<smiles>COS(=O)OCCCCOS(C)(=O)=O</smiles>

Busulfan or inhibitors of GST are considered to be the main sources of the interpatient variability of intravenous busulfan clearance $[8,9,11]$. Therapeutic drug monitoring and personalized drug dosing are recommended for any use of busulfan in conditioning regimens prior to HSCT [12]. According to current knowledge, elimination of treosulfan involves its nonenzymatic conversion to EBDM and DEB, and renal excretion of the unchanged prodrug [13]. Nevertheless, the interpatient variability of treosulfan clearance in HSCT patients after intravenous infusion of high doses (10-14 g/ $\left.\mathrm{m}^{2}\right)$ is rather appreciable, particularly in children [13, 14]. Following oral administration of a dose of $1 \mathrm{~g} / \mathrm{m}^{2}$ to adult females with ovarian cancer, the prodrug had almost complete bioavailability $(97 \pm 3 \%)$ [15]. The negligible firstpass effect suggests that, despite a structural similarity to busulfan, treosulfan undergoes no hepatic metabolism, but empirical evidence for this claim has not been provided to date [13]. Therefore, the aim of our study was to examine treosulfan-GSH conjugation in the presence or absence of a human liver cytosol, the main store of GST.

\section{Materials and Methods}

\subsection{Chemicals and Reagents}

Treosulfan was kindly supplied by Medac GmbH (Wedel, Germany). Human liver cytosol (20 mg protein/1 mL preparation in phosphate buffer), pooled from 46 adult donors representing different genders and race, was purchased from Life Technologies. GSH and racemic DEB, used as a positive control for testing the liver fraction activity, were obtained from Sigma-Aldrich. Acetonitrile and methanol, liquid chromatography (LC) gradient grade purity, and formic acid for LC were from Merck. Other chemicals, all of analytical grade, were also obtained from commercial suppliers. Demineralized water at a conductivity of $0.1 \mu \mathrm{S} / \mathrm{cm}$, prepared in a deionizer and filtered through a $0.45-\mu \mathrm{m}$ cellulose membrane filter, was always used.

\subsection{Preparation of a pH 7.2 Phosphate Buffer Saline for Metabolic Studies}

To prepare a phosphate buffer saline (PBS), $1.16 \mathrm{~g} \mathrm{KCl}$, $0.077 \mathrm{~g} \mathrm{KH}_{2} \mathrm{PO}_{4}$, and $0.286 \mathrm{~g} \mathrm{Na}_{2} \mathrm{HPO}_{4}$ were successively dissolved in $98 \mathrm{~mL}$ of water in a beaker. After $24 \mathrm{~h}$, the solution was placed in a water bath at $37{ }^{\circ} \mathrm{C}$, and adjusted to $\mathrm{pH} 7.18$ by the addition of $1 \mathrm{M} \mathrm{HCl}$. After reaching room temperature, the buffer was filled with water to $100 \mathrm{~mL}$ in a volumetric flask. The ionic strength of the PBS was $0.22 \mathrm{M}$. Following 10\% dilution with water, the solution changed its $\mathrm{pH}$ to 7.20 and lowered the ionic strength to $0.20 \mathrm{M}$, which provided the desired conditions for an in vitro metabolic study. It was found that $5 \mathrm{mM}$ GSH decreases the buffer $\mathrm{pH}$ from 7.20 to 6.79 , and the addition of $5.45 \mu \mathrm{L}$ of $1 \mathrm{M} \mathrm{NaOH}$ per $1 \mathrm{~mL}$ of the solution is required to compensate for the GSH effect.

\subsection{Treosulfan-GSH Conjugation Study}

A mixture of $350 \mu \mathrm{L}$ of $\mathrm{pH} 7.18$ phosphate buffer $(n=3)$, $20 \mu \mathrm{L}$ of freshly prepared $100 \mathrm{mM}$ GSH in water, $2.1 \mu \mathrm{L}$ of $1 \mathrm{M} \mathrm{NaOH}$, and $10 \mu \mathrm{L}$ of human liver cytosol was maintained at $37^{\circ} \mathrm{C}$ in a water bath, and the reaction was initiated 
by spiking with $20 \mu \mathrm{L}$ of the aqueous solution of $4 \mathrm{mM}$ treosulfan. As a result, the solution contained $200 \mu \mathrm{M}$ treosulfan, $0.5 \mathrm{mg} / \mathrm{mL}$ cytosolic proteins, and $5 \mathrm{mM} \mathrm{GSH}$. Samples $(40 \mu \mathrm{L})$ for kinetic analysis were collected at $0,0.25,0.5$, $1.0,1.5$, and $2.0 \mathrm{~h}$ into vials containing $10 \mu \mathrm{L}$ of $75 \mathrm{mM}$ citric acid to lower the $\mathrm{pH}$ to 4.6 , and thus prevent the artificial activation of treosulfan. To precipitate proteins, $60 \mu \mathrm{L}$ of methanol was added and the content was vortexed. Then, $10 \mu \mathrm{L}$ of water and $10 \mu \mathrm{L}$ of $0.5 \mathrm{mM}$ aqueous solution of codeine (internal standard) were spiked. The samples were centrifuged at $14,000 \mathrm{~g}$ at $4{ }^{\circ} \mathrm{C}$, for $5 \mathrm{~min}$, and the supernatant was analyzed with liquid chromatography-tandem mass spectrometry (LC-MS/MS). A positive control of the cytosol was carried out by incubating for $2 \mathrm{~h}$ with $250 \mu \mathrm{M}$ racemic DEB under the aforementioned conditions. A 2.3fold drop of the compound concentration (results not shown) was observed, which confirmed the enzymatic activity of the cytosol GST [16].

The nonenzymatic conjugation of treosulfan with GSH was examined in an analogous way as the enzymatic reaction, except $10 \mu \mathrm{L}$ of the cytosol in the reaction mixture was replaced with $10 \mu \mathrm{L}$ of the PBS. The collected samples ( $40 \mu \mathrm{L}$ ) were treated with $10 \mu \mathrm{L}$ of $50 \mathrm{mM}$ citric acid, $70 \mu \mathrm{L}$ of water, and $10 \mu \mathrm{L}$ of the codeine solution, and then subjected to the LC-MS/MS assay.

To determine the GSH-independent decay of treosulfan, the prodrug was incubated in only pH 7.2 PBS at $37{ }^{\circ} \mathrm{C}$. For that purpose, $360 \mu \mathrm{L}$ of PBS was mixed with $20 \mu \mathrm{L}$ of water, and then spiked with $20 \mu \mathrm{L}$ of $4 \mathrm{mM}$ treosulfan. The collected samples $(40 \mu \mathrm{L})$ were treated with $10 \mu \mathrm{L}$ of $50 \mathrm{mM}$ citric acid, $70 \mu \mathrm{L}$ of water, and $10 \mu \mathrm{L}$ of the codeine solution.

\subsection{LC-MS/MS Assay of Treosulfan}

The analysis was accomplished in Agilent 1260 apparatus coupled to Agilent 6410B Triple Quad. A Zorbax Eclipse Plus C18 column $(2.1 \times 100 \mathrm{~mm} ; 3.5 \mu \mathrm{m}$ particle size $)$ guarded by an Eclipse Plus C18 precolumn, both from Agilent, was maintained at $25^{\circ} \mathrm{C}$. The mobile phase consisted of $10 \mathrm{mM}$ ammonium formate-formic acid buffer, $\mathrm{pH} 4.0$ (eluent A) and acetonitrile (eluent B), and its flow was set at $0.5 \mathrm{~mL} / \mathrm{min}$. The following elution gradient program was used-0 min, $5 \% \mathrm{~B} ; 2.0 \mathrm{~min}, 5 \% \mathrm{~B} ; 10.0 \mathrm{~min}, 90 \%$ B; $10.1 \mathrm{~min}, 5 \% \mathrm{~B} ; 14.0 \mathrm{~min}, 5 \% \mathrm{~B}$. The injection volume was $5 \mu \mathrm{L}$. Ionization was accomplished with an electrospray interface working in a positive mode. Ionization source settings were capillary voltage $2000 \mathrm{~V}$, nebulizer gas pressure 60 psi $\left(\mathrm{N}_{2}\right)$, dry gas flow $10 \mathrm{~L} / \mathrm{min}\left(\mathrm{N}_{2}\right)$, and dry gas temperature $350{ }^{\circ} \mathrm{C}$. The detection was processed in a multiple reaction monitoring (MRM) mode using the following mass transitions-treosulfan $\mathbf{2 9 6 . 0} \rightarrow \mathbf{1 8 3 . 2}(5 \mathrm{eV}), 296.0 \rightarrow 278.7$ $(1 \mathrm{eV}), 296.0 \rightarrow 87.0(10 \mathrm{eV}) ;$ codeine $\mathbf{3 0 0 . 0} \rightarrow \mathbf{1 6 5 . 0}$
$(45 \mathrm{eV}), 300.0 \rightarrow 215.0(25 \mathrm{eV})$; transitions used for quantification are shown in bold and collision energies are given in brackets. The fragmentor voltage for the quantification of treosulfan and codeine was set at 94 and $130 \mathrm{~V}$, respectively. The MassHunter workstation software (Agilent Technologies, USA) was used for instrument control, data acquisition and data analysis. Calibration samples were prepared in a similar way to the samples collected during the kinetic study, except the citric acid-acidified drug-free suspension of the liver fraction in the phosphate buffer was spiked with $10 \mu \mathrm{L}$ of the standard solution of treosulfan instead of $10 \mu \mathrm{L}$ of water.

\subsection{Kinetic and Statistical Analysis}

Kinetic analysis was carried out using Excel 2010 (Microsoft Corporation). Rate constants for the decay of treosulfan in the studied samples were calculated from the slope of the linear plot of the natural logarithm of the treosulfan concentration versus time. Mandel's fitting test was applied to confirm the linearity of the obtained plots (a linear model is preferred over a quadratic one if the test value is lower than the critical value of $F_{\text {crit }}$. The statistical significance of the differences between the rate constants was evaluated in Statistica 10 (StatSoft Inc.) using analysis of variance (ANOVA) test.

\section{Results}

Treosulfan decayed according to a one-exponential model either in the presence or absence of human liver cytosol and GSH (Fig. 2). A linear plot of the natural logarithm of treosulfan concentrations versus time was confirmed by high values of the correlation coefficient obtained in all the

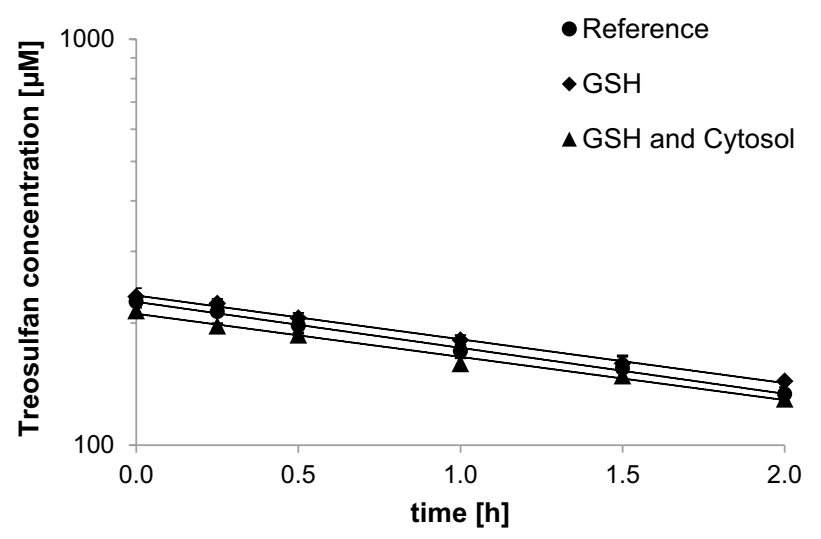

Fig. 2 Semilogarithmic plots of the treosulfan concentration (mean \pm standard deviation, $n=3$ ) in $\mathrm{pH} 7.2 \mathrm{PBS}$ at $37{ }^{\circ} \mathrm{C}$, in the absence (Reference) or presence of $5 \mathrm{mM} \mathrm{GSH}$ and/or human liver cytosol 
Table 1 Rate constants for the decay of treosulfan in the PBS solution at $\mathrm{pH} 7.2$, temperature $37^{\circ} \mathrm{C}$, and ionic strength $0.2 \mathrm{M}$

\begin{tabular}{lll}
\hline $\begin{array}{l}\text { Liver cytosol in the } \\
\text { solution (protein con- } \\
\text { centration) }\end{array}$ & $\begin{array}{l}\text { GSH in the solu- } \\
\text { tion (concentra- } \\
\text { tion) }\end{array}$ & $\begin{array}{l}\text { Reaction rate constant } \\
(\text { mean } \pm \mathrm{SD}, n=3) \\
{\left[\mathrm{h}^{-1}\right]^{\mathrm{a}}}\end{array}$ \\
\hline No & No & $0.261 \pm 0.030$ \\
No & $5 \mathrm{mM}$ & $0.248 \pm 0.008$ \\
$0.5 \mathrm{~g} / \mathrm{L}$ & $5 \mathrm{mM}$ & $0.245 \pm 0.014$ \\
\hline
\end{tabular}

GSH glutathione, $P B S$ phosphate buffer saline

${ }^{a}$ The ANOVA test showed no statistically significant differences between the reaction rate constants obtained under the investigated conditions

individual experiments (0.979-0.996) and the Mandel's fitting test results (tests values $0.003-31.0$ vs $F_{\text {crit }} 34.1$ ). The determined first-order reaction rate constants are presented in Table 1 . There was no statistically significant difference in the rate constants found for the samples containing the liver cytosol and GSH compared with the reference samples containing only PBS ( $p=0.50$ and 0.43 in the ANOVA test).

\section{Discussion}

In this study, we aimed to verify whether treosulfan can be metabolized via GSH conjugation, like its structural analog busulfan. For that purpose, we treated treosulfan with GSH at a concentration typical for hepatocytes $(5 \mathrm{mM})$, in the presence or absence of human liver cytosol, which is the main resource of GST in the body [17]. If treosulfan-GSH conjugation occurred, we expected to observe either a linear decline of the prodrug concentration in time (zero order kinetics due to enzyme saturation) or increased slope of its semilogarithmic plot due to a pseudo-first-order reaction with excessive GSH. However, neither of these scenarios took place (Fig. 2), which demonstrated that treosulfan does not undergo GST-mediated as well as spontaneous conjugation with GSH, at least at a noticeable rate. In the presence of liver cytosol and/or $\mathrm{GSH}$, the decomposition of treosulfan proceeded at the same rate as in the reference samples containing only PBS $\left(\sim 0.25 \mathrm{~h}^{-1}\right)$. This value reflected the $\mathrm{pH}$-dependent epoxidation of treosulfan to EBDM via an intramolecular bimolecular nucleophilic substitution [2,3]. Previously, busulfan has been found to react with GSH, both spontaneously and by GST-mediated catalysis, forming the sulfonium cation of GSH and releasing two methanesulfonate groups $[10,11]$. The lack of an analogous reaction for treosulfan might be explained on the grounds of the mechanism of the prodrug epoxidation to EBDM. This involves a very rapid $\left(3.3 \times 10^{5} \mathrm{~h}^{-1}\right.$ rate constant $)$ intramolecular attack of the deprotonated $\beta$-hydroxy group on the $\alpha$-carbon bearing the methanesulfonate group [3]. Substitution of the latter moiety by nucleophiles present in the solution is therefore highly unfavorable, which was confirmed by the lack of effect of acetate, chloride, phosphate, and carbonate anions on the kinetics of the treosulfan conversion to EBDM and DEB $[2,3]$. The findings of the present study that tripeptide nucleophile GSH does not visibly react with treosulfan agrees with the mentioned results and, in fact, provides additional support for the established mechanism of treosulfan epoxidation.

The resistance of treosulfan to GSH confirmed in this study is of clinical significance. The key implication will be the independence of treosulfan clearance of GST activity and GSH stores in the body. In particular, the genetic polymorphism of GST and physiological changes of the enzyme activity with age should have no effect on the interpatient variability of the drug clearance. This is important for reaching the target exposure of treosulfan applied in conditioning prior to HSCT in very young patients, including infants $[13,14]$. The other benefit lies in avoiding interactions with drugs that utilize GSH-dependent metabolic pathways, such as cyclophosphamide, melphalan, and thiotepa $[9,11]$. In conditioning regimens, these agents are usually administered within 1-2 days before or after treosulfan [18-21]. The lack of treosulfan conjugation with GSH may therefore prevent drug-drug competition for access to GST, depletion of GSH stores, and liver tissue injury. These phenomena supposedly occur when busulfan is co-administered with cyclophosphamide $[8,9,11]$. Hassan et al. [22] reported that prolongation of time between the last dosing of busulfan and starting cyclophosphamide (7-15 h to $24-50 \mathrm{~h}$ ) was associated with an increased clearance of busulfan and a lower incidence of sinusoidal obstructive syndrome. However, this kind of interaction between treosulfan and cyclophosphamide is unlikely in view of the results of the present work. Altogether, the resistance of treosulfan to GSH is expected to contribute to the relatively low hepatotoxicity of the prodrug due to saving the liver GSH stores.

\section{Conclusion}

Here, we have proved for the first time that treosulfan does not undergo either spontaneous or GST-mediated conjugation with GSH. This property of treosulfan is clinically beneficial because it prevents interpatient variability of the drug clearance due to GST activity, GSH depletion, and interactions with GSH-conjugated drugs. 


\section{Compliance with Ethical Standards}

Funding This work was supported by the Poznan University of Medical Sciences, grant No. 502-14-33064130-09629. The Ministry of Science and Higher Education (Poland) sponsored the open access publication under Springer's Open Choice option.

Conflict of Interest M. Romański and F.K. Główka declare no conflict of interest.

Open Access This article is distributed under the terms of the Creative Commons Attribution-NonCommercial 4.0 International License (http://creativecommons.org/licenses/by-nc/4.0/), which permits any noncommercial use, distribution, and reproduction in any medium, provided you give appropriate credit to the original author(s) and the source, provide a link to the Creative Commons license, and indicate if changes were made.

\section{References}

1. Sehouli J, Tomè $\mathrm{O}$, Dimitrova $\mathrm{D}$, Camara $\mathrm{O}$, Runnebaum IB, Tessen HW, Rautenberg B, Chekerov R, Muallem MZ, Lux MP, Trarbach T, Gitsch G. A phase III, open label, randomized multicenter controlled trial of oral versus intravenous treosulfan in heavily pretreated recurrent ovarian cancer: a study of the NorthEastern German Society of Gynecological Oncology (NOGGO). J Cancer Res Clin Oncol. 2017;143:541-55.

2. Romański M, Urbaniak B, Kokot Z, Główka FK. Activation of prodrug treosulfan at $\mathrm{pH} 7.4$ and $37^{\circ} \mathrm{C}$ accompanied by hydrolysis of its active epoxides: kinetic studies with clinical relevance. J Pharm Sci. 2015;104:4433-42.

3. Romański M, Ratajczak W, Główka FG. Kinetic and mechanistic study of the pH-dependent activation (epoxidation) of prodrug treosulfan including the reaction inhibition in a borate buffer. $\mathrm{J}$ Pharm Sci. 2017;106:1917-22.

4. Hartley JA, O'Hare CC, Baumgart J. DNA alkylation and interstrand cross-linking by treosulfan. Br J Cancer. 1999;79:264-6.

5. Nemecek ER, Guthrie KA, Sorror ML, Wood BL, Doney KC, Hilger RA, Scott BL, Kovacsovics TJ, Maziarz RT, Woolfrey AE, Bedalov A, Sanders JE, Pagel JM, Sickle EJ, Witherspoon R, Flowers ME, Appelbaum FR, Deeg HJ. Conditioning with treosulfan and fludarabine followed by allogeneic hematopoietic cell transplantation for high-risk hematologic malignancies. Biol Blood Marrow Transplant. 2011;173:341-50.

6. Boztug H, Sykora KW, Slatter M, Zecca M, Veys P, Lankester A, Cant A, Skinner R, Wachowiak J, Glogova E, Pötschger U, Peters C. European Society for Blood and Marrow Transplantation analysis of treosulfan conditioning before hematopoietic stem cell transplantation in children and adolescents with hematological malignancies. Pediatr Blood Cancer. 2016;63:139-48.

7. Remberger M, Törlen J, Serafi IE, Garming-Legert K, Björklund A, Ljungman P, Sundin M, Hassan M, Mattsson J. Toxicological effects of fludarabine and treosulfan conditioning before allogeneic stem-cell transplantation. Int J Hematol. 2017;106:471-5.

8. Ciurea SO, Andersson BS. Busulfan in hematopoietic stem cell transplantation. Biol Blood Marrow Transplant. 2009;15:523-36.

9. Nath CE, Shaw PJ. Busulphan in blood and marrow transplantation: dose, route, frequency and role of therapeutic drug monitoring. Curr Clin Pharmacol. 2007;2:75-91.

10. Gibbs JP, Czerwinski M, Slattery JT. Busulfan-glutathione conjugation catalyzed by human liver cytosolic glutathione S-transferases. Cancer Res. 1996;56:3678-81.
11. Myers AL, Kawedia JD, Champlin RE, Kramer MA, Nieto Y, Ghose R, Andersson BS. Clarifying busulfan metabolism and drug interactions to support new therapeutic drug monitoring strategies: a comprehensive review. Expert Opin Drug Metab Toxicol. 2017;13:901-23.

12. Palmer J, McCune JS, Perales M-A, Marks D, Bubalo J, Mohty M, Wingard JR, Paci A, Hassan M, Bredeson C, Pidala J, Shah N, Shaughnessy P, Majhail N, Schriber J, Savani BN, Carpenter PA. Personalizing busulfan-based conditioning: considerations from the American Society for Blood and Marrow Transplantation Practice Guidelines Committee. Biol Blood Marrow Transplant. 2016;22:1915-25.

13. Romański M, Wachowiak J, Główka FK. Treosulfan pharmacokinetics and its variability in pediatric and adult patients undergoing conditioning prior to hematopoietic stem cell transplantation: current state of the art, in-depth analysis, and perspectives. Clin Pharmacokinet. 2018;57:1255-65.

14. van der Stoep MYEC, Bertaina A, Ten Brink MH, Bredius RG, Smiers FJ, Wanders DCM, Moes DJAR, Locatelli F, Guchelaar HJ, Zwaveling J, Lankester AC. High interpatient variability of treosulfan exposure is associated with early toxicity in paediatric HSCT: a prospective multicentre study. Br J Haematol. 2017;179:772-80.

15. Hilger RA, Jacek G, Oberhoff C, Kredtke S, Baumgart J, Seeber S, Scheulen ME. Investigation of bioavailability and pharmacokinetics of treosulfan capsules in patients with relapsed ovarian cancer. Cancer Chemother Pharmacol. 2000;45:483-8.

16. Boogaard PJ, Sumner SC, Bond JA. Glutathione conjugation of 1,2:3,4- diepoxybutane in human liver and rat and mouse liver and lung in vitro. Toxicol Appl Pharmacol. 1996;136:307-16.

17. Forman HJ, Zhang H, Rinna A. Glutathione: overview of its protective roles, measurement, and biosynthesis. Mol Aspects Med. 2009;30:1-12.

18. Choudhary D, Sharma SK, Gupta N, Kharya G, Pavecha P, Handoo A, Setia R, Katewa S. Treosulfan-thiotepa-fludarabine-based conditioning regimen for allogeneic transplantation in patients with thalassemia major: a single-center experience from north India. Biol Blood Marrow Transplant. 2013;19:492-5.

19. Sauer M, Zeidler C, Meissner B, Rehe K, Hanke A, Welte K, Lohse P, Sykora KW. Substitution of cyclophosphamide and busulfan by fludarabine, treosulfan and melphalan in a preparative regimen for children and adolescents with Shwachman-Diamond syndrome. Bone Marrow Transplant. 2007;39:143-7.

20. Chemnitz JM, von Lilienfeld-Toal M, Holtick U, Theurich S, Shimabukuro-Vornhagen A, Krause A, Brossart P, Hallek M, Scheid C. Intermediate intensity conditioning regimen containing FLAMSA, treosulfan, cyclophosphamide, and ATG for allogeneic stem cell transplantation in elderly patients with relapsed or highrisk acute myeloid leukemia. Ann Hematol. 2012;91:47-55.

21. Kröger N, Bornhäuser M, Stelljes M, Pichlmeier U, Trenschel R, Schmid C, Arnold R, Martin H, Heinzelmann M, Wolschke C, Meyer RG, Bethge W, Kobbe G, Ayuk F, Gökbuget N, Hölzer D, Zander A, Beelen D. Allogeneic stem cell transplantation after conditioning with treosulfan, etoposide and cyclophosphamide for patients with ALL: a phase II-study on behalf of the German Cooperative Transplant Study Group and ALL Study Group (GMALL). Bone Marrow Transplant. 2015;50:1503-7.

22. Hassan M, Ljungman P, Ringdén O, Hassan Z, Oberg G, Nilsson C, Békassy A, Bielenstein M, Abdel-Rehim M, Georén S, Astner L. The effect of busulphan on the pharmacokinetics of cyclophosphamide and its 4-hydroxy metabolite: time interval influence on therapeutic efficacy and therapy-related toxicity. Bone Marrow Transplant. 2000;25:915-24. 